\title{
Tree-ring evidence of the widespread effects of explosive volcanic eruptions
}

\author{
P.D. Jones, K.R. Briffa and F.H. Schweingruber* \\ Climatic Research Unit, University of East Anglia, Norwich, U K
}

\begin{abstract}
Tree-ring evidence from 97 sites over North America and Europe are used to develop a chronology of widespread cool summers since 1600 . Averaging annual maximum-density information from the chronologies provides an index that correlates with Northern Hemisphere summer temperatures to 0.44 over 1851-1975. A number of the extreme low density years occur in both North America and Europe, suggesting a common response to high-frequency forcing. The analysis was repeated with ring-width information but the results are markedly less coherent. Of the five common extreme lowdensity years $(1601,1641,1669,1699$ and 1912) four are known to be coincident with the year or year following major volcanic eruptions. Other extreme low density indices in the continental series are also clearly coincident with known volcanoes. The density indices clearly demonstrate great potential for quantifying the climate effectiveness and perhaps establishing precise calendar dates of large explosive volcanoes.
\end{abstract}

\section{Introduction}

The potential for large explosive volcanic eruptions to influence weather and climate on regional and hemispheric scales has been much discussed in the literature (Lamb, 1970 and Bradley, 1988). Numerous studies using instrumental temperature records and historical evidence of the timing and character of particular eruptions have sought to confirm and quantify the decreases in surface air temperatures expected to follow such eruptions (Sear et al., 1987). Before the last one to two hundred years both the spatial coverage of instrumental temperature records and the completeness of the historic volcano record become increasingly poor and our ability to explore the pattern and magnitude of the volcano-climate link is severely hampered (Bradley and Jones, 1992).

Indirect (or so-called proxy) records, provided they are welldated and of sufficient resolution, offer some prospect of extending our knowledge both of volcanic activity and the associated changes in temperature. Changes in the level of acidity or sulphate concentrations at different depths in highlatitude and high-altitude ice cores represent changes in the amount of volcanically-produced aerosols deposited on the ice sheet (Hammer et al., 1980 and Zielinski et al., 1994). Hence peaks in ice-core acidity may be used to develop a paleovolcanic

\footnotetext{
*Swith Federal Institute for Forest, Snow and Landscape Research, Zürcherstrasse, Birmensdorf, Ch-8903, Switzerland.
}

\section{Copyright 1995 by the American Geophysical Union.}

\author{
Paper number 94GL03113 \\ 0094-8534/95/94GL-03113\$03.00
}

index, although the magnitude of such peaks in any individual core may not allow the definite identification (Legrand and Delmas, 1987) of the source or the amount of the stratospheric input (Clausen and Hammer, 1988) of specific eruptions, or their climatic significance.

Tree-rings with their annual resolution and absolute dating accuracy represent an important source of proxy climate data (Fritts, 1976 and Schweingruber, 1988). Where such records predominantly represent temperature forcing, attempts have been made to identify the volcanic influence in tree-ring or treering-derived temperature series (LaMarche and Hirschboek, 1984 and Scuderi, 1990). Individual tree-ring or temperature records may be influenced by volcanoes, but they are subject to other forms of natural variability which are not related to volcanism and which could obscure or exaggerate the apparent effects (Pyle, 1992 and Scuderi, 1992). Volcanic effects on hemispheric-scale temperature are thought, on the basis of 20 th century evidence, to be both statistically significant but relatively small (Sear et al., 1987).

During the last decade, with the long-term aim of reconstructing large-scale regional temperature patterns, an extensive program of tree-ring sampling has been undertaken by the Swiss Federal Institute for Forest, Snow and Landscape Research (Schweingruber et al., 1991).

This work, which has attempted to reconstruct large-scale patterns of "summer" temperature variability, has also provided circumstantial evidence that volcanic activity may be one identifiable influence, although to an extent which varies with region (Briffa et al., 1992, 1994). Here, we take the opportunity to examine the evidence for large-regional-scale volcanic forcing of MXD and TRW variability using these networks of data over North America and Europe.

\section{Data and Analysis}

The tree-ring information (MXD and TRW) used in this analysis consists of 97 sites in North America and 37 sites in Europe specifically selected for being temperature sensitive. The North American sites were taken from two sampling expeditions, 53 sites in western North America (Schweingruber et al., 1991) and 44 sites in Canada from the Mackenzie Valley region to Labrador (Schweingruber et al., 1993). The latest available years in each of these sets of data are 1983 and 1988, respectively. The 37 European sites which all extend to at least 1975 are described in Briffa et al. (1988a). The length of the individual chronologies obviously varies from site to site. For North America there are 23 chronologies which begin before 1600 and for Europe there are four. All the analyses use the data spanning the years 1600 to 1975 .

All chronologies were used here, as 'standardised' in the original publications (cited above). Standardization here involves removing low-frequency variance in the original measurements, much of which represents biologically-related 
trends. The subsequent analysis is therefore focused on relatively high-frequency tree-ring information. This situation is synonymous with the removal of 'background' sulphate levels in ice-core records prior to the identification of volcanic peaks (e.g. Zielinski et al., 1994). Slightly different techniques were used to standardise the various groups of tree-ring data but the similar effective frequency responses of the methods means that this does not affect the results to any meaningful extent.

Extremes in the MXD and TRW series were identified by transforming the individual series into z-scores using the mean and standard deviation from the 1901-75 period common to all sites. Continental averages were then derived by a weighted average of all the site $Z$ values available for that year. The weighting was the number of cores available in a given year as a fraction of the total number of cores at each site. The formula is:

$$
Z_{j}=\sum_{i=1}^{P} n_{y j} a_{y j} / n_{\max } / \sum_{i=1}^{P} n_{i j} / n_{\max }
$$

where $P$ is the number of sites available in year $j$

$\mathrm{n}_{\mathrm{ij}}$ is the maximum number of cores available in year $\mathrm{j}$ at site $\mathrm{i}$ $\mathbf{n}_{\max }$ is the number of cores available at site $i$

and $a_{i j}$ is the normalised value of the MXD and TRW series in year $\mathrm{j}$ at site $\mathrm{i}$

We also tried an alternative method of ranking the MXD and TRW series over the entire length ( $N$ years) of each chronology. The year with the lowest value is given the value $1 / \mathrm{N}$, the second $2 / \mathrm{N}$ etc. This method gives almost the same series as that using $Z$.

\section{Results}

Correlations between MXD and TRW for each continent only just reach the $95 \%$ significance level. The correlation between the "merged" (the weighted average of the two continents) MXD index and summer (June to August) temperatures (highfrequency departures from a 20-year Gaussian filter) over the Northern Hemisphere (land areas only - data from Jones, 1994, available only since 1851 - see, also, Jones and Briffa, 1992) is 0.44 . For TRW, the correlation is 0.22 .

Table 1 lists the 20 most extreme negative values in the MXD series. In Table 1, there are five years in common (1601, 1641, 1669 and 1912), between Europe and North America. For TRW, there are no extreme negative years in common between Europe and North America.

\section{Discussion}

The common occurrence of five years in the lists of most extreme negative indices for MXD in North America and Europe is highly significant $(p=0.003)$. This significance was calculated by Monte Carlo methods (100,000 simulations) selecting two sets of 20 years randomly from 376 and checking for common years. Four of the five years are definitely concurrent with or immediately follow known highly explosive volcanic eruptions (Simkin et al., 1981). The fifth year (1699) was almost certainly due to another eruption. The index for 1601 is exceptional $(-2.72)$ as it is more than double the magnitude of that in 1641 , the second most extreme. This implies a very large and widespread temperature reduction, particularly in the westem United States (Briffa et al., 1992) in the year following the eruption of Huaynaputina, Peru. The extreme index value for this year in both the continental indices is strong evidence that the eruption was much larger than appreciated, or was perhaps concurrent with another eruption as suggested by Zielinski et al., (1993).

The 1641 density index $(-1.23)$ is contemporary with the eruption of Awu, Indonesia (VEI of 5 on the Simkin et al., 1981 scale) and one year after the eruptions of Komaga-Take, Japan and Llaima, Chile (both VEI 4). The low values in 1668 (12th) and 1669 (4th) follow the eruption of Tarumai, Japan (VEI 5 in 1667). They are principally due to low density values in North America and may also be due to the large eruption of Long Island, New Guinea (VEI 6), dated at about 1700 in Simkin et al. (1981) but recently redated to $1660 \pm 20$ (see Zielinski et al., 1994). The index value in 1912 (10th smallest) corresponds with the eruption of Katmai, Alaska.

Other years in the merged (North America and Europe) index correspond with well-known eruptions: 1816 (11th) and 1817 (18th) follow the eruption of Tambora, Indonesia in 1815. These years showed marked cooling in tree-ring based reconstructions (Briffa et al., 1988a, 1994; Schweingruber et al., 1991) in western Europe and eastern North America, but not in western North America (Briffa et al., 1992). The 1810 value is mainly the result of low density values in the North American trees and has been cited as evidence of the climatically effective eruption assumed on the basis of ice core evidence to have occurred in 1808 or 1809 (Briffa et al., 1994). Other years with low density values in one or other of the continents may be potentially related to known eruptions: 1835 (Conseguina, Nicaragua); 1740 (Tarumai, Japan); 1812 and 1814 (Soufrière, West Indies in both years, but also Mayon, Philippines, 1814). Not all the low density indices, however, are associated with known volcanic years, notably 1612 in North Amenca and 1675 in Europe. These may just reflect non-volcano-related cool summers but their magnitude justifies some speculation that they could be related to unknown eruptions.

Table 1. Extreme negative years for MXD

\begin{tabular}{rlccccc}
\hline & \multirow{2}{*}{ North America } & \multicolumn{2}{c}{ Europe } & \multicolumn{2}{c}{ Merged } \\
\hline & Year & Val & Year & Val & Year & Val \\
\hline 1 & 1601 & -2.59 & 1601 & -3.44 & 1601 & -2.72 \\
2 & 1612 & -1.42 & 1675 & -2.49 & 1641 & -1.23 \\
3 & 1641 & -1.18 & 1619 & -1.76 & 1612 & -1.11 \\
4 & 1643 & -1.02 & 1600 & -1.74 & 1669 & -1.00 \\
5 & 1669 & -1.01 & 1816 & -1.50 & 1643 & -0.99 \\
6 & 1668 & -0.97 & 1641 & -1.48 & 1699 & -0.88 \\
7 & 1819 & -0.93 & 1652 & -1.42 & 1621 & -0.86 \\
8 & 1810 & -0.92 & 1695 & -1.37 & 1695 & -0.85 \\
9 & 1621 & -0.90 & 1742 & -1.17 & 1698 & -0.83 \\
10 & 1702 & -0.84 & 1835 & -1.15 & 1912 & -0.81 \\
11 & 1801 & -0.83 & 1617 & -1.13 & 1816 & -0.72 \\
12 & 1701 & -0.83 & 1699 & -1.09 & 1668 & -0.71 \\
13 & 1699 & -0.81 & 1605 & -1.07 & 1810 & -0.70 \\
14 & 1698 & -0.79 & 1912 & -1.03 & 1604 & -0.69 \\
15 & 1725 & -0.78 & 1716 & -1.02 & 1899 & -0.69 \\
16 & 1809 & -0.73 & 1740 & -1.00 & 1968 & -0.65 \\
17 & 1880 & -0.73 & 1714 & -0.99 & 1701 & -0.64 \\
18 & 1732 & -0.73 & 1812 & -0.98 & 1817 & -0.63 \\
19 & 1817 & -0.73 & 1814 & -0.98 & 1702 & -0.62 \\
20 & 1912 & -0.72 & 1669 & -0.97 & 1837 & -0.61 \\
\hline
\end{tabular}


It is also interesting to note the absence of certain years, such as 1884 and 1903 from both the continental and the merged indices in Table 2. Cool summers might be expected in these years as they follow two VEI 6 eruptions at Krakatau, Indonesia (1883) and Santa Maria, Guatemalà (1902). The value for 1884 is relatively low in the merged index (28th lowest with $\mathrm{Z}=$ -0.54). This suggests that Krakatau did have a noticeable cooling effect, but it may not have been as great (at least in the summer) as the VEI implies. This conclusion is supported by recent studies of instrumental temperature records (Robock and Mao, 1995). The three Caribbean eruptions in 1902 (Santa Maria, Pelée and Soufrière) did not, however, produce a large negative extreme in any of the density indices (the value in the merged series is 0.09). Prolonged cooling of global mean temperatures did occur after these eruptions (Jones and Kelly, 1988) but the cooling in the summer of 1903 did not occur in the regions where the trees were growing.

This serves to warn against any simplistic interpretation of the tree-ring indices as being directly indicative of volcanic forcung. Previous work linking 20th century explosive volcanoes and instrumental temperature data indicates the possibility of diverse effects depending on the location (latitude), timing (season), composition (sulphur content of ejecta) and the atmospheric circulation state (was an EI Niño event occurring?) at the time of the eruption (Jones and Kelly, 1988; Robock and Mao, 1992). It is also clear, however, that high VEI values should not be taken as proof of major climatic effects (Newhall and Self, 1982). Similarly, high sulphate layers in ice cores is not definite evidence of high stratospheric loading. For example, the eruption of Laki, Iceland in 1783 resulted in large sulphate peaks in 1783 and 1784 in GISP2 and other Greenland cores (Fiacco et al., 1995). Instrumental temperature in Europe do not show consistently cold temperatures in either year or in 1785. Low-density yalues in northern European tree-ring sites are restricted to western Norway (particularly the Lofoten Islands) and may be associated primarily with tropospheric fall out (see also Briffa et al., 1988b, 1994) from the well reported sulphuric haze (the sites are the closest to Iceland and wind directions at the time of the eruption would have taken the material due east in the westerly circulation (Thordarson and Self, 1993).

It is not our intention to imply that the density indices we show here represent a direct index of volcanic activity or aerosol optical depths However, they do represent a crude index of continental-scale summer temperatures. Clearly, low summer temperatures can occur without a volcanic cause, just as the presence of volcanic aerosols does not always lead to cold summers, where our trees grow. Nevertheless, most extreme negative density indices appear to be related to major volcanic eruptions and we consider that this preliminary study demonstrates significant potential for providing independent evidence of the climatic effectiveness of major eruptions proposed on the basis of ice core and historic evidence.

\section{Conclusions}

Averages of maximum latewood density (MXD) and ring width (TRW) values from a network of 97 sites in North America and 37 sites in westem Europe, specifically selected for being temperature sensitive, have been used to examine the evidence for large-scale volcanic forcing of the temperature of the Northern Hemisphere. The two regions were analysed separately and it was found that the results for MXD were more continentally coherent than those for TRW. Five years were among the 20 most extreme MXD years in both regions. These were $1601,1641,1669,1699$ and 1912. All except 1699 are known volcano years and this analysis suggests that it, along with 1612 and 1675, should be considered as additional candidates.

The method proposed for the development of a tree-ring index of explosive volcanic eruptions is an efficient method of using much more tree-ring information than is currently employed in considering volcano-climate links. Longer and better replicated MXD series can be developed for North America and Eurasia (extending across Russia) will improve the value of the index.

\section{Acknowledgements}

The collection and processing of the primary densitometric data base was supported by grants from the Swiss National Science Foundation (FHS). The authors thank Stephen Self and Gregory Zielinski for comments which strengthened the manuscript. This work has been supported by the European Community (KRB) under Grant No. EV5V-CT94-0500 (DG12 DTEE) and by the U.S. Department of Energy (PDJ), Atmospheric and Climatic Research Division under Grant No. DE-FG02-86ER60397.

\section{References}

Bradley, R. S., The explosive volcanic eruption signal in Northern Hemisphere continental temperature records, Climatic Change 12, 221-243, 1988.

Bradley, R. S., and P. D. Jones, Records of explosive volcanic eruptions over the last 500 years, in Climate Since A.D. 1500 , edited by R. S. Bradley and P. D. Jones, Routledge, London, 606-622, 1992.

Briffa, K. R., P. D. Jones, and F. H. Schweingruber, Summer temperature patterns over Europe: A reconstruction from A.D. 1750 based on maximum latewood density indices of conifers, Quaternary Research 30, 36-52, 1988a.

Briffa, K. R., P. D. Jones., J. R. Pilcher, and M. K. Hughes, Reconstructing summer . temperatures in northern Fennoscandinavia back to A.D. 1700 using tree-ring data from Scots Pine, Arctic and Alpine Research 20, 385-394, $1988 \mathrm{~b}$.

Briffa, K. R., P. D. Jones, and F. H. Schweingruber, Tree-ring reconstructions of summer temperature patterns across western North America since 1600, Journal of Climate 5 , 735-754, 1992.

Briffa, K. R., P. D. Jones, and F. H. Schweingruber, Summer temperatures across northern North America: regional reconstructions from 1760 using tree-ring densities, Journal of Geophysical Research 99, 25835-25844, 1994

Clausen, H. B., and C. U. Hammer, The Laki and Tambora eruptions as revealed in Greenland ice cores from 11 locations. Annals of Glaciology 10, 16-22, 1988.

Fiacco, R. J. Jr., T. Thordarson., M. S. Germani., S. Self., J. M. Palais., S. Whitlow, and P. Grootes, Atmospheric loading and transport due to the 1783-84 Laki eruption interpreted from ash particles and acidity in the GISP2 ice core, Quaternary Research (in press).

Fritts, H. C., Tree Rings and Climate. Academic Press, London, 1976. 
Hammer, C. U., M. B. Clausen, and W. Dansgaard, Greenland ice-sheet evidence of post-glacial volcanism and its climatic impact, Nature 288, 230-235, 1980.

Jones, P. D., Hemispheric surface air temperature variations: a reanalysis and an update to 1993, Journal of Climate 7, 1794-1802, 1994.

Jones, P. D., and K. R. Briffa, Global surface air temperature variations over the twentieth century: Part 1 Spatial, temporal and seasonal details, The Holocene 2, 174-188, 1992.

Jones, P. D., and P. M. Kelly, Causes of interannual global temperature variations over the period since 1861, in $\mathrm{H}$. Wanner and U. Siegenthaler Eds, Lecture Notes in Earth Sciences 16, Springer-Verlag, Berlin, 18-34, 1988.

LaMarche, V. C., Jr, and K. K. Hirschboek, Frost rings in trees as records of major volcanic eruption, Nature 307, 121-126, 1984.

Lamb, H. H., Volcanic dust in the atmosphere, with a chronology and assessment of its meteorological significance, Phil. Trans. Royal Soc. London, Series A 266, 425-533, 1970.

Legrand, M., and R. J. Delmas, A 220-year continuous record of volcanic $\mathrm{H}_{2} \mathrm{SO}_{4}$ in the Antarctic ice sheet, Nature 327, 671676, 1987.

Newhall, C. G., and S. Self, The Volcanic Explosivity Index (VEI): an estimate of explosive magnitude for historical volcanism, Journal of Geophysical Research 87, 1231-1238, 1982.

Pyle, D. M., On the 'Climatic Effectiveness' of volcanic eruptions, Quaternary Research 37, 125-129, 1992.

Robock, A., and J. Mao, Winter warming from large volcanic eruptions, Geophysical Research Letters 19, 2405-2408, 1992.

Robock, A., and J. Mao, J., The volcanic signal in surface temperature observations, Journal of Climate (in press).

Schweingruber, F. H., Tree Rings, Basics and Applications of Dendrochronology, D. Reidel, Dordrecht, 1988.

Schweingruber, F. H., K. R. Briffa, and P. D. Jones, Yearly maps of summer temperatures in western Europe from A.D. 1750 and western North America from 1600 to 1982: results of a radio densitometrical study on tree rings, Vegetatio 92 , 5-71, 1991.
Schweingruber, F. H., K. R. Briffa, and P. Nogler, A tree-ring densitometric transect from Alaska to Labrador. Comparison of ring-width and maximum-latewood-density chronologies in the conifer belt of northern North America, International Journal of Biometeorology 37, 151-169, 1993.

Scuderi, L. C., Tree-ring evidence for climatically effective volcanic eruptions, Quaternary Research 34, 67-85, 1990.

Scuderi, L. C., Climatically effective volcanism, Quaternary Research 37, 130-135, 1992.

Sear, C. B., P. M. Kelly., P. D. Jones, and C. M. Goodess, Global surface temperature responses to major volcanic eruptions, Nature 330, 365-367, 1987.

Simkin, T. P., L. Siebert., L. McCelland., D. Bridge., C. Newhall, and J. H. Latter, Volcanoes of the World, Hutchinson-Ross, Stroudsberg, 1981.

Thordarson, T., and S. Self, The Laki (Skaftar Fires) and Grimsvotn eruptions in 1783-1785, Bull Volc., 55, 233-263, 1993.

Zielinski, G. A., P. A. Mayewski., S. Whitlow., M. Twickler., M. Morrison, and L. D. Meeker, Atmospheric sulfate loading from large (VEI >5) equatorical eruptions over the last 2000 years as estimated from a summit, Greenland, ice core, paper presented at IAVCEI General Assembly, Camberra (Abstract), 129, 1993.

Zielinski, G. A., P. A. Mayewski., L. D. Meeker., S. Whitlow., M. S. Twickler., M. Morrison., D.A. Meese., A. J. Gow, and R. B. Alley, Record of Volcanism since 7000 BC from GISP2 Greenland Ice Core and implifications for volcano-climate system, Science 264, 948-952, 1994.

P. D. Jones and K. R. Briffa, Climatic Research Unit, University of East Anglia, Norwich NR4 7TJ, UK.

F. H. Schweingruber, Swiss Federal Institute for Forest, Snow and Landscape Research, Zürcherstrasse, Birmensdorf, $\mathrm{CH}-8903$, Switzerland.

(Received July 28, 1994; revised November 1, 1994; accepted November 9, 1994.) 